\title{
FOREIGN LANGUAGE EDUCATION IN THE MILITARY
}

\author{
Marioara PATEŞAN*, Dana ZECHIA** \\ *6"Nicolae Bălcescu" Land Forces Academy, Sibiu, Romania \\ **“Mircea cel Bătrân" Naval Academy, Constanţa, Romania \\ mpatesan@yahoo.com, dzechia@yahoo.com
}

\begin{abstract}
As teachers of English in the military, we totally believe that today's military should have foreign language skills and cultural expertise besides military competencies, needed to face the challenges of our present security. Foreign languages and cultural awareness can be considered 'critical capabilities'. But proficiency in a foreign language is difficult to be acquired when you are not allotted sufficient class hours or the linguistic level of your students is pretty low. The English language proficiency training is a complex process involving time as well as human and financial resources. Each army needs literate military in foreign languages that can speak and write, comprehend oral speech or written text, in the literal and figurative forms of the language. Not being able to speak the NATO prime language of communication can be considered a real barrier for any military participant in international missions. The present study is a theoretical approach presenting some priorities in language learning education at home and abroad.
\end{abstract}

Keywords: second language acquisition, linguistic competence, language professionals

\section{Introduction}

Second language acquisition is a complex procedure, and learners vary widely in their learning abilities. In everyday life language helps us to express our feelings, emotions and questions to the people around us but in the case of the military having a foreign language and cultural expertise is essential in sustaining coalitions, maintaining regional stability, and conducting multinational missions in humanitarian, nationbuilding, stability operations, and security. Language and cultural understanding are important assets in an efficient working and cooperating with any coalition partners in any multicultural environment. Not only the leaders but also the regular forces should have the right blend of culture and foreign language knowledge, skills, and professional expertise. Knowing a foreign language and having cultural awareness creates more positive attitudes and less prejudice toward people who are different. Studying a foreign language is more than linguistic acquisition; it implies developing of the communication skills, enhancing listening, reading comprehension or writing skills, problem solving, dealing with abstract concepts or a more profound understanding of one's own culture, thus making a person more flexible and tolerant. In short, it can make a person lead out with commitment and trust in his/her own forces.

\section{Language professionals}

Being able to communicate directly with different people in their native language is one of the first steps to founding a lasting, stable personal or business relationship but when it comes to the military be them land, 
naval or air forces it may become a matter of life or death not only for a person but for all in direct subordination during a combat mission. Mastering a foreign language is not just learning grammar and vocabulary; it is learning and using expressions in order to communicate appropriately as well as having enough cultural information to understand other cultures. The term "language professionals" refers to personnel who possess a verified foreign language capability and require this capability to perform their primary functions.[1] It seems that the first to realize the need for foreign languages competences for the military were the Americans. They believe that "there is no doubt that foreign language skills and cultural expertise are critical capabilities needed by today's military to face the challenges of our present security environment" as they recognized "the need and provided the impetus, for both cultural awareness and enhanced pre-deployment language preparation".[2] In recent years the Department of Defense explicitly identify foreign language skills and regional expertise as "critical war fighting skills" that must be integrated into future operations "to ensure that combat forces deploy with the essential ability to understand and effectively communicate with native populations, local and government officials, and Coalition partners when in theater." [3]

More than that strengthening foreign language and cultural awareness capabilities is one of the 25 top priorities of the DOD among the Department's top 25 transformations.

Priorities as the Irregular Warfare Joint Operating Concept calls on the services to train the force so that "a pool of linguistically and culturally educated personnel capable of operating in priority countries" exists throughout the joint force, not just the special operations force.[4]

Thus The Defense Language Institute Foreign Language Center in Monterey, California DLIFLC is "DoD's premier school for culturally based foreign language education and training, with classroom instruction, mobile training teams, and online materials tailored for students at all levels of required proficiency or performance. The institute that started its program started as early as 1941 at the Presidio of San Francisco, only six weeks before Pearl Harbor, is attended by all four branches of the military service and select individuals sponsored by their agencies." [5]

In the United Kingdom Ministry of Defense's centre for Language and Culture based within the Defense Academy, Shrivenham, is "responsible for providing foreign language training to UK Armed Forces personnel and English language training for foreign defense forces and defense civil servants, in order to enhance military capability for operations and contribute to the International Defense Engagement Strategy as well as "training to NATO standards across the four language skills - listening, speaking, reading and writing."[6]

\section{Language certification: structures and documents}

The objective of E 0356 "Language requirements for deployable forces" is Romania's commitment to the North Atlantic Alliance through which military personnel participating in NATO-led actions are certified to possess good and very good English language levels; the certification is done in accordance with the provisions of the STANAG 6001Standardization Agreement "Levels of linguistic competence". The standardized language profile represents the level of knowledge of a foreign language in accordance with the rules established by NATO and the assessment of foreign language knowledge is carried out in a unitary system, by reference to unique criteria, in order to meet the requirements of international media posts allocated to Member States. 
As a result of this, by the approval of the Minister of National Defense of February 2008 the National Military Testing Center for Foreign Languages is established as the single responsible structure within the Ministry of National Defense, which has the mission to assess the level of linguistic competence of staff in order to establish a standardized linguistic profile (PLS) according to NATO-agreed standards.

The center was set up in accordance with the SHAPE / NATO Directives issued in 2004 and 2006 respectively, which refer to the "Policy Statement on Ensuring Language and Professional Skills" and "Linguistic Testing". The center's activity is monitored by NATO's competent structures, and the linguistic competence certificates issued by the Center have a validity of 4 years and are recognized in the Ministry of National Defense and NATO Alliance Commands as well.

The NATO 6001 Standardization Agreement "Levels of Language Competence" (STANAG 6001) provides for the assessment of foreign language knowledge to be carried out in a unitary system, by reference to unique criteria, in order to meet the requirements of international media posts allocated to Member States. [7]

\section{Standardized linguistic agreements 3.1 STANAG 6001 background}

If we agree that "language skills ... are now seen as critical operational capabilities just as important as weapons - on the battlefield and across the entire array of Departmental missions we can explain the need for an international office to coordinate language learning and to unify the assessment of proficiency levels foe NATO members and partners. [8]

It all started back in 1966 when the Bureau for International Language Coordination (BILC) was established in 1966 as NATO's consultative and advisory body for language training and testing issues. BILC is custodian for STANAG 6001 and among its main objectives are: to sponsor and maintain STANAG 6001 language proficiency levels and to enhance interoperability of individual language education and training through standardization achieved by a common understanding of language descriptors and assessment protocols." as the memorandum of cooperation of November 2011, Norfolk stated. [9]

NATO adopted the standards that were drafted by BILC during 1973 through 1975 but the lack of consistent specifications limited the STANAG's usefulness for assessment purposes.

In 1976 STANAG $60011^{\text {st }}$ Edition was not a success as the brevity of the descriptions allowed for multiple interpretations. That is why in 1999: BILC formed a working group on Testing and Assessment having the goal to elaborate on and interpret the original STANAG 6001 descriptors and in the year 2000 the working group produced the "Interpretation and Elaboration Document" that was piloted in a BILC language training seminar. It took three years to release STANAG 6001, Edition 2 was released after the approval by the NATO Standardization Agency in 2002. Along the next years the working group made substantial changes and after extensive study and work the testing began in May, 2009 when 200 Benchmark Advisory Tests (BAT) BAT were allocated across 11 Nations. These tests were needed to promote consistent interpretation and interpretation of STANAG 6001 across national testing programs.

It was that year's Edition 3 when a major change occurred so as the levels to better reflect the content of the level descriptions, as follows:

- Level $0=$ No proficiency.

- Level 1 = Elementary Survival.

- Level 2 = Fair Functional.

- Level $3=$ Good Professional.

- Level 4 = Very Good Expert. 
- Level $5=$ Excellent Highlyarticulate native.

That year's edition defined language proficiency as "unrehearsed, general language communication ability" and added descriptions of "plus levels" as: "A plus level is understood to be more than halfway between two base levels and it substantially exceeds the base level, but does not fully or consistently meet all of the criteria for the next higher base level" while Edition 4 of 2010 added that: "A plus level may be added to a base level for training, evaluation, recording or reporting purposes." Edition 5 took place in 2014 when the format and introductory pages were modified but the standards were not changed. In 2017 the annual conference took place in Vienna, Austria where BILC got two requests: to investigate the portability of NATO military language certification into civilian terms and vice versa and to decide if Language Education can be integrated into Military Training and Exercises more efficiently.[10] Today BILC has active members from 23 NATO nations and 10 Partner nations.

\subsection{Common European Framework of Reference for Languages}

The Council of Europe developed the Common European Framework of Reference for Languages: learning teaching, assessment (CEFR). The document points out to the importance of developing language competences in foreign languages, so as learners be able to communicate in many different languages and situations.

The Common European Framework of Reference for Languages: Learning, teaching, assessment (CEFR) is a framework of reference, a guideline used to describe "achievements of learners of foreign languages across Europe and, increasingly, in other countries". It was designed "to provide a transparent, coherent and comprehensive basis for the elaboration of language syllabuses and curriculum guidelines, the design of teaching and learning materials, and the assessment of foreign language proficiency. It is used in Europe but also in other continents being available in 40 languages. [11]

It divides general competences in knowledge, skills and communicative competences. The CEFR distinguishes between four kinds of language activities: reception (listening and reading), production (spoken and written), interaction (spoken and written), and mediation (translating and interpreting). The Common European Framework divides learners into "three broad divisions that can be divided into six levels; for each level, it describes what a learner is supposed to be able to do in reading, listening, speaking and writing. A language user can develop various degrees of competence in each of these domains and to help describe them the CEFR has provided a set of six Common Reference Levels ".

- Level A: A1 = Breakthrough or beginner

$$
\text { A2 = Waystage or elementary }
$$

- Level B: B1= Threshold or intermediate

$$
\text { B2 = Vantage or upper }
$$
intermediate

- Level C: $\mathrm{Cl}=$ Effective operational proficiency or advanced

$\mathrm{C} 2=$ Mastery or proficiency [12]. The learners are required oral skills (to be able to present knowledge and experiences, to participate in discussions, to present / interpret literary texts, to talk on various issues), reading skills (to understand content of written texts to interpret and reflect upon literature of all genres, to understand and analyze a broad spectrum of textual forms, compose texts master tools for gathering information, composing and presenting texts. [13]

\section{Conclusion}

No matter if a military takes part in a conflict, a humanitarian act or a face -toface negotiation to set conditions for a military course of action, language and 
culture matter. Acquisition of a foreign language "promotes the knowledge, attitudes and skills relevant to living responsibly in a multicultural, interdependent world" [14]

Our military students will not only be professionals but also socially responsible world citizens so they should study a foreign language as a core competence as they have to master the knowledge, skills, and attitudes of the language. Once our cadets start taking part in international missions English will become essential, crucial in coordinating of the teamwork, in transforming the decisions of the higher ranks into commands to subordinates so necessary for the success of a mission. As teachers of English we should strive to boost the quality of our graduates' linguistic communication skills by offering both a strict and attractive curriculum.

\section{References}

[1] http://www.jcs.mil/Library/CJCS-Instructions/ Chairman of the Joint Chiefs of Staff Instruction, Language and Regional Expertise Planning (CJCSI), 2008.

[2] Building Language Skills and Cultural Competencies in the Military: DOD's Challenge in Today's Educational Environment, U.S. House of Representatives, Committee on Armed Services, Subcommittee on Oversight \& Investigations, Washington, DC, Approved for public release.

[3] http://www.jcs.mil/Library/CJCS-Instructions/Chairman of the Joint Chiefs of Staff Instruction, Language and Regional Expertise Planning (CJCSI), 2008.

[4] Department of Defense The Irregular Warfare Joint Operating Concept, 11 September 2007.

[5] http://www.dliflc.edu/, retrieved in 25.02.2018.

[6] https://www.da.mod.uk/colleges-and-schools/defence-centre-for-languages-andculture/english-language-wing, retrieved in 27.02.2018.

[7] https://dmru.mapn.ro, retrieved in 15.02.2018.

[8] http://culture.af.mil/nce/PDF/mission/ncemission02.pdf: Department of Defense Summit: June 2007, DoD Regional and Cultural Capabilities, The Way Ahead.

[9] https://www.natobilc.org/en/products/policy-documents-bilc-documents/, retrieved in 20.02.2018.

[10] https://www.natobilc.org/en/ retrieved in 20.02.2018.

[11] https://www.coe.int/en/web/common-european-framework-reference-languages/, retrieved in 25.02.2018.

[12] https:/www.coe.int/en/web/common-european-framework-reference-languages/, retrieved in 25.02.2018.

[13] AASE Laila, Matching skills with needs, Aims in the Teaching/Learning of Intergovernmental Conference Languages of Schooling: towards a Framework for Europe, Strasbourg 16-18 October 2006.

[14] Fisher, S. and Hicks D., World Studies 8-13. New York: Oliver \& Boyd, p 8, 1985. 